NBER WORKING PAPER SERIES

BANKS ARE WHERE THE LIQUIDITY IS

Oliver Hart

Luigi Zingales

Working Paper 20207

http://www.nber.org/papers/w20207

\author{
NATIONAL BUREAU OF ECONOMIC RESEARCH \\ 1050 Massachusetts Avenue \\ Cambridge, MA 02138 \\ June 2014
}

We would like to thank Arnoud Boot, Christian Leuz, Alp Simsek, Vania Stavrakeva, Robert Vishny, and participants in seminars at MIT, the University of Chicago, Cass Business School, LSE (finance), Boston College, and the University of Amsterdam for useful comments, and Kirill Borusyak for research assistance. Oliver Hart gratefully acknowledges financial support from the U.S. National Science Foundation through the National Bureau of Economic Research. Luigi Zingales gratefully acknowledges financial support from the Center for Research in Security Prices (CRSP) and the Initiative on Global Markets at the University of Chicago. The views expressed herein are those of the authors and do not necessarily reflect the views of the National Bureau of Economic Research.

NBER working papers are circulated for discussion and comment purposes. They have not been peerreviewed or been subject to the review by the NBER Board of Directors that accompanies official NBER publications.

(C) 2014 by Oliver Hart and Luigi Zingales. All rights reserved. Short sections of text, not to exceed two paragraphs, may be quoted without explicit permission provided that full credit, including $₫$ notice, is given to the source. 
Banks Are Where The Liquidity Is

Oliver Hart and Luigi Zingales

NBER Working Paper No. 20207

June 2014

JEL No. E41,E51,G21

\begin{abstract}
$\underline{\text { ABSTRACT }}$
What is so special about banks that their demise often triggers government intervention? In this paper we develop a simple model where, even ignoring interconnectedness issues, the failure of a bank causes a larger welfare loss than the failure of other institutions. The reason is that agents in need of liquidity tend to concentrate their holdings in banks. Thus, a shock to banks disproportionately affects the agents who need liquidity the most, reducing aggregate demand and the level of economic activity. In the context of our model, the optimal fiscal response to such a shock is to help people, not banks, and the size of this response should be larger if a bank, rather than a similarly-sized nonfinancial firm, fails.
\end{abstract}

Oliver Hart

Department of Economics

Littauer Center 220

Harvard University

Cambridge, MA 02138

and NBER

ohart@harvard.edu

Luigi Zingales

Booth School of Business

The University of Chicago

5807 S. Woodlawn Avenue

Chicago, IL 60637

and NBER

luigi.zingales@ChicagoBooth.edu 
During the 2007-2008 financial crisis industrial firms, including major ones like General Motors, were allowed to go bankrupt. By contrast, financial firms, with the notable exception of Lehman, were bailed out. One possible reason for this differential treatment can be found in the political clout of these two industries. Financial firms were and are major donors of recent administrations. Many of the recent Treasury Secretaries and White House Chiefs of Staff had close ties to the financial industry. The greater attention shown by the government toward the financial industry, thus, might be purely a matter of politics. While not denying this possibility, in this paper we explore an alternative interpretation: that government intervention is justified by an intrinsic difference in the welfare consequences when a bank, rather than an equally-sized industrial firm, fails.

An often-mentioned rational for this difference is the degree of interconnectedness of financial institutions. But while there is no doubt that large financial institutions tend to be highly interconnected, large industrial firms like General Motors and Ford are very interconnected too. To quote Ford's CEO Alan Mulally: “The domestic auto industry is highly interdependent. A collapse of one of our competitors would not only affect Ford and our transformation plan, but would have a devastating ripple effect across the economy."1

Another popular interpretation among financial economists for the difference between large manufacturing firms and banks focuses on the ability of depositors to run (e.g., Diamond and Dybvig, 1983), raising the possibility of inefficient liquidation. Yet, suppliers and customers of GM can run too, a concern that led the U.S. Government to intervene in 2008 to guarantee GM warranties. So what makes banks different?

In this paper, we focus on a different dimension: banks are special because they are where people in need of liquidity keep their wealth. In a world where the return from human capital is not fully pledgeable, there is a natural demand for safe (or relatively safe) assets to support trading. Banks arise to satisfy this need. As a result, we will show that agents who need liquidity for transaction purposes will

\footnotetext{
${ }^{1}$ Alan Mulally's testimony to the United States Senate Committee on Banking, Housing and Urban Affairs, November 18, 2008.
} 
hold their wealth disproportionately in the form of bank deposits (or similar financial securities—see below).

In a world where the return from human capital is not fully pledgeable, the failure of any firm implies two losses: a direct loss of wealth, and an indirect loss in liquidity resulting from the reduction in pledgeable assets. This dual effect is present both for a bank and for an industrial firm. Yet, the impact of a loss of pledgeable assets is different depending on the liquidity needs of the holders of those assets. A bank failure disproportionately hits agents who are liquidity constrained (more so than if an industrial firm was to fail), causing a larger drop in the demand for labor services that was supported by that liquidity, and a larger fall in GDP. (Similarly, a loss borne by debt-holders affects GDP disproportionately more than an equally-sized loss borne by equity investors.)

Building on Hart and Zingales (2013), we consider a simple general equilibrium economy where security markets are complete, but consumers cannot pledge future income or wealth, including labor income. There are two groups of agents and the lack of a simultaneous double coincidence of wants between the two groups generates the need for a relatively safe asset for transaction purposes. In this context we show that agents with liquidity needs (in our model, those who buy before they sell) will choose to hold a disproportionate amount of (Arrow) securities that pay off in the low states of the world.

We also show that these Arrow securities can be manufactured by tranching investment payoffs in order of seniority. If we build Arrow securities in this way, the agents in need of liquidity will hold disproportionately more of the most senior tranches, which are relatively safe. Unlike the classic literature (e. g., Baumol (1952) and Tobin (1956)) that focuses on the transactional demand for money, our model derives a transactional demand for safe assets. It is a way to formalize the source of the shortage of safe assets proclaimed by Caballero (2006). The fundamental friction is the same as that stressed by Caballero et al. (2008): as a result of limited pledgeability, the world's ability to generate wealth has outpaced its ability to generate safe stores of value and to credibly transfer that wealth. As we show in Section 6 this "shortage" persists even in the presence of government debt. 
Given the demand for safe assets, we consider the macroeconomic effects of imposing a loss on the different tranches underlying investor returns. There is a built-in correlation between extremely negative aggregate outcomes and losses borne by the most senior tranches. To eliminate this effect, we consider only losses resulting from an idiosyncratic fraud in a specific tranche: we call this a "Madoff" shock. If we did not, the effect we observe would be even larger.

We show that, when a shock hits senior tranches, the macroeconomic effect of this shock is more severe and so is the welfare loss associated with it. Losses borne by senior tranche holders deprive the agents who need liquidity of collateral. In so doing, they reduce the effective demand of these agents for the services of other agents, decreasing the amount of income these other agents can make. Unable to sell their labor services on favorable terms, the other agents will curtail their own demand for services, further reducing the overall level of economic activity. This effect is more limited or even completely absent when a junior tranches face a loss, because junior tranches are held disproportionately by agents with low liquidity needs.

The very senior tranches held by liquidity-constrained agents look similar to bank deposits. Indeed, banks can be considered as mutual funds that on the asset side invest in financial claims and on the liability side have a disproportionate share of very senior claims (deposits). According to this view, banks are nothing but a cost-effective way to manufacture safe assets needed for transaction purposes. This simple theory of banking is able to explain why banks need to have deposits that do not fluctuate in value. Depositors are the agents with the highest need for liquidity and thus they demand insurance against possible falls in the value of their investments, even if they are risk neutral. In our model this insurance is provided by the agents less in need of liquidity.

This very simple theory of banking is able to explain not only why the default of a bank is worse than the default of a similarly-sized industrial company, but also why these effects are not unique to banks: they are common to all the most senior securities. This might also explain why governments are so reluctant to impose losses on bonds, especially secured bonds. The reason is the same: they are held disproportionately by people in need of liquidity. Finally, the theory can explain why the size of the fiscal 
response to a shock is larger if a bank, rather than a similarly-sized nonfinancial firm, fails. Yet, our model would suggest that the government intervention should be targeted to help people with liquidity needs, not banks per se.

As we will show, our results can also explain why the bursting of the internet bubble had relatively mild macroeconomic effects, while the (milder) loss in subprime mortgages had a devastating impact. The former shock was concentrated on equity instruments held by people with no compelling liquidity needs, while the latter shock impacted relatively senior claims held by people with compelling liquidity needs (see also Mian and Sufi, 2014).

Note that we would not have obtained the same results had we assumed that the demand for safe assets came from agents’ risk aversion. In a complete markets model, agents with different risk aversion will trade so as to equalize their marginal rates of substitution. Thus, on the margin the welfare loss is the same regardless of which group of agents is hit by the shock. By contrast, in our model the welfare effects depend upon who is hit.

A risk-aversion based model would also be unable to explain why riskless debt has a yield lower than that predicted by a risk-return tradeoff (Krishnamurthy and Vissing-Jorgensen (2012)). To explain riskless debt's lower yield, several papers have postulated a special demand for riskless securities (e.g., Hanson et al. (2014), Krishnamurthy and Vissing-Jorgensen (2012) and Stein (2012)). In this paper we derive this demand from first principles, in so doing providing foundations for the monetary policy results obtained by Stein (2012) and the differences between traditional and shadow banks emphasized by Hanson et al. (2014).

The rest of the paper proceeds as follows. Section 2 presents the framework. Section 3 characterizes the non-pledgeable equilibrium for the case where there is insufficient liquidity in each state of the world to sustain the first-best level of trade. (One of the sub-cases is relegated to an Appendix.) Section 4 shows how this demand can be satisfied by securities' tranches and how the most senior tranches will be disproportionately held by those who are liquidity constrained. Section 5 extends the analysis to the case where there is sufficient liquidity in the best state of the world to sustain the first-best 
level of trade. Section 6 considers the role of fiscal policy. Section 7 explains how our very senior funds can be interpreted as banks. Finally, Section 8 concludes.

\section{The Framework}

There are many agents. Ex ante each agent is equally likely to be a type that buys before it sells or a type that sells before it buys; agents learn their type at the beginning of period 1 . We call the first type financial planners and the second type secretaries. (Aide-memoire: financial planners buy first and secretaries buy second.) Financial planners want to consume secretarial services in period 2 and secretaries want to consume financial planning services in period 3. Financial planners and secretaries can also consume wheat in period 4 and there is no discounting. Each financial planner and secretary has an endowment of wheat in period 1 equal to $e$. Wheat can be invested in projects; these projects yield wheat in period 4 . We will assume that $e>0$. The timeline is as in Figure 1.

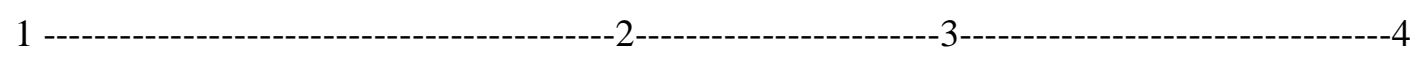

$\begin{array}{llllc}\begin{array}{l}\text { Agents learn whether } \\ \text { they are financial planners } \\ \text { or secretaries }\end{array} & \begin{array}{l}\text { State of world } \\ \text { realized }\end{array} & \begin{array}{l}\text { Trade of } \\ \text { secretarial } \\ \text { Wheat invested }\end{array} & \begin{array}{l}\text { Trade of } \\ \text { financial planning } \\ \text { services }\end{array} & \begin{array}{c}\text { Output } \\ \text { from projects }\end{array} \\ \text { Services } & & \text { / wheat } \\ \text { consumed }\end{array}$

Securities traded

Figure 1

We write agents' utilities as:

$$
\begin{gathered}
\text { Financial Planners: } U^{f}=w^{f}+s^{f}-\frac{1}{2}\left(l^{f}\right)^{2} \\
\text { Secretaries: } U^{s}=w^{s}+f^{s}-\frac{1}{2}\left(l^{s}\right)^{2}
\end{gathered}
$$

where $s^{f}$ is the quantity of secretarial services consumed by a financial planner; $l^{f}$ is the labor supplied by a financial planner; $f^{s}$ is the quantity of financial planning services consumed by a secretary; $l^{s}$ is 
the labor supplied by a secretary; and $w^{i}$ is the quantity of wheat consumed by individual $i=f, s$ in period 4. We assume constant returns to scale: one unit of secretarial labor yields one unit of secretarial services and one unit of financial planning labor yields one unit of financial planning services.

In other words financial planners (resp., secretaries) are indifferent between wheat and secretarial (resp., financial planning services) and have a quadratic disutility of labor.

Agents are risk neutral. The markets for secretarial and financial planning services are perfectly competitive. It is crucial for our analysis that there is no simultaneous double coincidence of wants: a secretary does not want to consume financial planning services in period 2 from the financial planner who is buying his secretarial services.

There is a risky technology that transfers endowment between periods 1 and 4 . There are $n$ (aggregate) states of the world. With probability $\pi_{i}>0$, one unit of period 1 wheat is transformed into $R_{i}$ units of period 4 wheat $(i=1, \ldots n)$. Without loss of generality we label the states so that $0<R_{1}<R_{2}<\ldots .<R_{n}$. Agents learn about the state of the world between periods 1 and 2 . All agents are risk neutral. We also assume that there is free entry of firms possessing the technology described and that these firms face constant returns to scale (the firms’ technologies are perfectly correlated).

This framework is similar to Hart and Zingales (2013), except in three respects. One (minor) is that there are $n$ states instead of just 2. The second (more important) is that we do not assume that an agent can insure against becoming a financial planner rather than a secretary before period 1; a justification is that period 1 endowment cannot be pledged in advance (ex post an agent can hide it). Third, and most important, in this model there is no riskless storage. As we show in Hart and Zingales (2013), the presence of multiple investment choices creates a distortion between private and social incentives. Since this distortion has already been analyzed in our other paper, we want to eliminate it here. In spite of these differences, some of the basic results are the same. For example, in the absence of any pledgeability problem the economy has a unique Arrow-Debreu (or sequential Arrow) equilibrium. In this equilibrium, there is a separation between consumption and production. Since the model is 
symmetric, the prices of financial planning and secretarial services, the wage rates of financial planners and secretaries, and the price of wheat will be the same, and we can normalize them to be 1 in each state of the world. At these prices each financial planner and secretary supplies and consumes one unit of services, incurs a labor cost of $1 / 2$, and receives a consumer surplus of $1 / 2$. Agents also receive expected

surplus $e \sum_{i}^{n} \pi_{i} R_{i}$ from investing their endowment, and so the utility of each agent is $e \sum_{i}^{n} \pi_{i} R_{i}+\frac{1}{2}$.

Finally, since the rate of return in the economy is $\bar{R}=\sum_{i}^{n} \pi_{i} R_{i}$, the equilibrium price of an Arrow

security, which pays off one unit of wheat in state $i$, is $\pi_{i} / \bar{R}$.

\section{Non-pledgeable Equilibrium for the case where $2 e R_{n}<1$}

Consider now the case where future labor income cannot be pledged (i.e., workers can hide their income from lenders). Suppose, however, that project returns can be pledged (the firms carrying out the projects might be public companies, say). That is, firms can invest period 1 wheat in the risky project and issue securities collateralized by the project returns (project returns cannot be stolen by firms' managers). These securities will be purchased in period 1 by financial planners and secretaries and used as a means of payment for services in periods 2 and 3. Since we do not wish to introduce further frictions it is natural to assume that the state of the world is verifiable and that firms issue a full set of Arrow securities backed by their projects (where security $i, i=1, \ldots, n$, pays off a unit of wheat if and only if state $i$ occurs).

Let us review the timing. Agents learn their type at the beginning of period 1. Arrow security markets open, and firms invest. The state of the world, state $i$ say, is learned at the end of period 1 . At this point Arrow security $i$ has value 1 (in terms of period 4 wheat) and all other Arrow securities have value zero. In period 2 financial planners use their holdings of Arrow security $i$ to buy secretarial services. In period 3 secretaries use their holdings of security $i$ acquired in period 1, plus what they have accumulated 
from financial planners in return for supplying secretarial services in period 2, to buy financial planning services. In period 4 investments pay off and wheat is consumed.

In this section we suppose that $2 e R_{n}<1$; we consider the case $2 e R_{n}>\mathbf{l}$ in Section 5. To compute the non-pledgeable equilibrium, normalize so that the prices of wheat in period 1, wheat in period 4, Arrow security i in period 2, and Arrow security i in period 3, are all one (if state i occurs). Consider a financial planner's utility maximization problem. In equilibrium the price of secretarial services in period 2 cannot exceed 1 since otherwise financial planners would strictly prefer to use their securities to purchase period 4 wheat rather than secretarial services, and so the secretary market would not clear. Thus, we can assume for the purpose of calculating utility that financial planners use all their Arrow securities to buy secretarial services. (By a parallel argument the price of financial planning services in period 3 cannot exceed 1 and so for purposes of calculating utility we can assume that secretaries spend all their Arrow securities on financial planning services.) Next consider a financial planner's labor supply decision in period 3. Ignore the subscript on the state. Then a financial planner will choose his labor supply $l^{f}$ to maximize $p^{f} l^{f}-\frac{1}{2}\left(l^{f}\right)^{2}$, i.e., set $l^{f}=p^{f}$, where $p^{f}$ is the price of financial planner services. Note that it is too late for the financial planner to buy more secretarial services and so his marginal return from work is $p^{f}$ (he will use the proceeds to buy wheat in period 4). A financial planner's labor yields revenue $\left(p^{f}\right)^{2}$, which he redeems for wheat in period 4; in addition he incurs an effort cost of $\frac{1}{2}\left(p^{f}\right)^{2}$, and so his net utility from work is $\frac{1}{2}\left(p^{f}\right)^{2}$.

It follows that in period 1 a financial planner chooses his holdings of Arrow securities $\left(x_{i}^{f}, i=1\right.$, ...n) to solve:

$$
\operatorname{Max} \sum_{i} \pi_{i}\left[\frac{x_{i}^{f}}{p_{i}^{s}}+\frac{1}{2}\left(p_{i}^{f}\right)^{2}\right]
$$




$$
\text { s.t. } \sum_{i}^{n} q_{i} x_{i}^{f} \leq e
$$

where $p_{i}^{f}, p_{i}^{s}$ are the prices of financial planning and secretarial services, respectively, in state $i$ and $q_{i}$ is the period 1 price of the ith Arrow security. Note that firm profits are zero in equilibrium given constant returns to scale, and so we do not need to keep track of any dividends received by consumers. Note also that $x_{i}^{f} \geq 0$, since a short seller cannot credibly commit to pay ex post.

A similar calculation applies to secretaries. The difference is that a secretary in period 2 chooses her labor supply $l^{s}$ to maximize $\frac{p^{s}}{p^{f}} l^{s}-\frac{1}{2}\left(l^{s}\right)^{2}$, where $p^{s}$ is the price of secretarial services. The reason is that a secretary's marginal return from work is $\frac{p^{s}}{p^{f}}$, since she will use her income to buy financial planning services. Thus a secretary's net utility from work is $\frac{1}{2}\left(\frac{p^{s}}{p^{f}}\right)^{2}$. Hence in period 1 a secretary chooses her holdings of Arrow securities $\left(X_{i}^{s}, j=1, \ldots n\right)$ to solve:

$$
\operatorname{Max} \sum_{i} \pi_{i}\left[\frac{x_{i}^{s}}{p_{i}^{f}}+\frac{1}{2}\left(\frac{p_{i}^{s}}{p_{i}^{f}}\right)^{2}\right]
$$

subject to

$$
\sum_{i}^{n} q_{i} x_{i}^{s} \leq e
$$

where $x_{i}^{s} \geq 0$ for the same reason stated above.

As noted, profit maximization and constant return to scale imply zero profit:

$$
\sum_{i}^{n} q_{i} R_{i}=1
$$

Since all the wheat is invested, the supply of the ith Arrow security is $2 e R_{i}$. Hence, the securities market clearing conditions are 


$$
x_{i}^{f}+x_{i}^{s}=2 e R_{i} \text {, for } i=1, \ldots n \text {. }
$$

It is easy to see that in equilibrium $x_{i}^{f}>0$ for all $i$ : if $x_{i}^{f}=0$, the price of the secretarial services in state $i$ would be zero and the return to a financial planner of purchasing an Arrow security in that state would be infinite. Also, since we have assumed that $2 e R_{n}<1$, even in the best state the supply of liquidity is not enough to support the Arrow-Debreu level of trade and so prices of financial planning and secretarial services will be strictly below 1. It follows that financial planners and secretaries will spend all their available wealth on each other's services in periods 2 and 3. Given the supply functions for financial planning and secretarial services obtained earlier, we can write the market clearing conditions for financial planning and secretarial services in state $i$ as

$$
\begin{aligned}
& \frac{x_{i}^{f}}{p_{i}^{s}}=\frac{p_{i}^{s}}{p_{i}^{f}}, \\
& \frac{x_{i}^{f}+x_{i}^{s}}{p_{i}^{f}}=p_{i}^{f}, \text { for } i=1, \ldots n .
\end{aligned}
$$

$(*),(* *),(3.1)$ - (3.4) characterize a non-pledgeable equilibrium.

Although $x_{i}^{f}>0$ for all $i$, it is less clear that $x_{i}^{s}>0$ for all $i$. In the text we will concentrate on the case where $x_{i}^{s}>0$ for all $i$ : we show that a sufficient condition for this is $\sum_{j} \pi_{j} R_{j}^{\frac{1}{2}}<2 R_{1}^{\frac{1}{2}}$. In the appendix we establish that our results generalize to the case where $x_{i}^{s}=0$ for some $i$.

Proposition 1: Let $S=\sum_{j} \pi_{j} R_{j}^{\frac{1}{2}}$, and suppose that $S<2 R_{1}^{\frac{1}{2}}$. Then there is a unique non-pledgeable equilibrium characterized by

$$
\begin{gathered}
q_{i}=\frac{\pi_{i}}{R_{i}^{\frac{1}{2}} S}, \\
x_{i}^{f}=e R_{i}^{\frac{1}{2}} S,
\end{gathered}
$$




$$
\begin{gathered}
x_{i}^{s}=2 e R_{i}-e R_{i}^{\frac{1}{2}} S>0, \\
p_{i}^{f}=\left(2 e R_{i}\right)^{\frac{1}{2}} \\
p_{i}^{s}=2^{\frac{1}{4}} R_{i}^{\frac{1}{2}} e^{\frac{3}{4}} S^{\frac{1}{2}}
\end{gathered}
$$

for all $i$.

Proof: Suppose $x_{i}^{s}>0$. Then, the first order conditions for $(*)$ and $(* *)$ are:

$$
\begin{gathered}
\frac{\pi_{i}}{q_{i} p_{i}^{s}}=k_{1}, \\
\frac{\pi_{i}}{q_{i} p_{i}^{f}}=k_{2},
\end{gathered}
$$

for all $i$, for some $k_{1}, k_{2}$.

From (3.2) -(3.4),

$$
p_{i}^{f}=\left(2 e R_{i}\right)^{\frac{1}{2}} \text { and } p_{i}^{s}=\left(x_{i}^{f}\right)^{\frac{1}{2}}\left(2 e R_{i}\right)^{\frac{1}{4}} \text {, }
$$

and so

$$
\begin{gathered}
\frac{\pi_{i}}{q_{i}\left(x_{i}^{f}\right)^{\frac{1}{2}}\left(2 e R_{i}\right)^{\frac{1}{4}}}=k_{1}, \\
\frac{\pi_{i}}{q_{i}\left(2 e R_{i}\right)^{\frac{1}{2}}}=k_{2} .
\end{gathered}
$$

In turn, this implies

$$
\left(x_{i}^{f}\right)^{\frac{1}{2}}=\frac{k_{2}}{k_{1}}\left(2 e R_{i}\right)^{\frac{1}{4}} .
$$

From (3.1) and (3.9) 


$$
\sum_{j} \frac{\pi_{j} R_{j}}{\left(2 e R_{j}\right)^{\frac{1}{2}}}=k_{2}=\frac{S}{(2 e)^{\frac{1}{2}}}
$$

Substituting (3.11) into (3.9), we have

$$
q_{i}=\frac{\pi_{i}}{\left(R_{i}\right)^{\frac{1}{2}}} \frac{1}{S}
$$

From (3.10)- (3.11) and the budget constraint $\sum_{j} q_{j} x_{j}^{f}=e$, we have

$$
k_{1}^{2}=\frac{S}{2^{\frac{1}{2}} e^{\frac{3}{2}}},
$$

and so we can write

$$
\begin{aligned}
& x_{i}^{f}=e R_{i}^{\frac{1}{2}} S, \\
& p_{i}^{s}=2^{\frac{1}{4}}\left(R_{i}\right)^{\frac{1}{2}} e^{\frac{3}{4}} S^{\frac{1}{2}} .
\end{aligned}
$$

We have established the formulae in Proposition 1. The only remaining thing to check is that $x_{i}^{s}>0$, i.e., $x_{i}^{f}<2 e R_{i}$. This will be true as long as

$$
e R_{i}^{\frac{1}{2}} S<2 e R_{i} \text { for all } i
$$

i.e., $S<2 R_{1}^{\frac{1}{2}}$.

It is clear that the above is a non-pledgeable equilibrium. The argument in the appendix establishes uniqueness.

Q.E.D.

Proposition 1 tells us that a financial planner's demand for Arrow securities $x_{i}^{f}$ is strictly increasing in $i$. It is also easy to see that a secretary's demand for Arrow securities, $x_{i}^{s}=2 e R_{i}-e R_{i}^{\frac{1}{2}} S$, is 
strictly increasing in $i$ (given $2 R_{1}^{\frac{1}{2}}>S$ ). Both of these results are intuitive. (They are akin to co-

insurance results when parties are risk-averse.) In better states the supply of Arrow securities is greater, their price lower, and parties will hold more of them.

The next proposition tells us that a financial planner's demand for Arrow securities exceeds a secretary's demand in the lowest state $i=1$ and the reverse is the case in the highest state $i=n$. Also the demands cross only once.

Proposition 2: $x_{1}^{f}>x_{1}^{s}, x_{n}^{f}<x_{n}^{s}$, and there exists an $i^{*}$ such that $x_{i}^{f} \geq x_{i}^{s}$ for $i \leq i^{*}$ and $x_{i}^{f}<x_{i}^{s}$ for $i>i^{*}$.

Proof: Consider

$$
x_{i}^{f}-x_{i}^{s}=2 e\left[R_{i}^{\frac{1}{2}} S-R_{i}\right]
$$

This is positive for $i=1$ since $\sum_{j} \pi_{j} R_{j}^{\frac{1}{2}}>R_{1}^{\frac{1}{2}}$ and negative for $i=n$ since $\sum_{j} \pi_{j} R_{j}^{\frac{1}{2}}<R_{n}^{\frac{1}{2}}$. Also if $x_{i^{*}}^{f}-x_{i^{*}}^{s} \leq 0$, i.e., $R_{i^{*}}^{\frac{1}{2}} \geq \sum_{j} \pi_{j} R_{j}^{\frac{1}{2}}$, then for $i>i^{*} R_{i^{*}}^{\frac{1}{2}}>\sum_{j} \pi_{j} R_{j}^{\frac{1}{2}}$ and so $x_{i}^{f}-x_{i}^{s}<0$.

Q.E.D.

Proposition 2 is also intuitive. Liquidity is more important for financial planners than for secretaries, and it is relatively more this way in low states of the world.

\section{Tranching of Securities}

So far we have shown that financial planners want relatively more Arrow securities in the low states and secretaries in the high states. Given the number of states of the world, it is worthwhile to consider whether this demand can be satisfied by "simpler" securities. In this section we will prove that both types of agents' demand for securities can be satisfied by tranching the payoff of an investment in the existing technology on the basis of seniority, similar to the tranching of collateralized debt obligations that was so 
popular before the 2008 financial crisis. (For a different explanation of tranching, based on asymmetric information, see DeMarzo (2005).) We will also analyze the welfare effects of losses incurred by securities with different levels of seniority.

\subsection{Tranches as a viable substitute for Arrow securities}

Let's start by proving that both the financial planners' and the secretaries' demand for Arrow securities can be satisfied by tranches on the economy's return stream $\left(R_{1}, R_{2}, \ldots R_{n}\right)$. A tranche corresponds to a debt level of a certain seniority. If the tranches are $d_{1}, d_{2}, d_{3}, . ., d_{k}$ in descending order of seniority, then in state $i$ the first tranche receives $\operatorname{Min}\left(d_{1}, \tilde{R}\right)$, the second tranche $\operatorname{Min}\left(d_{2}, \tilde{R}-\operatorname{Min}\left(d_{1}, \tilde{R}\right)\right)$, the third tranche $\operatorname{Min}\left(d_{3}, \tilde{R}-\operatorname{Min}\left(d_{1}, \tilde{R}\right)-\operatorname{Min}\left(d_{2}, \tilde{R}-\operatorname{Min}\left(d_{1}, \tilde{R}\right)\right)\right)$, and so on.

Proposition 3: The demand for $n$ Arrow securities by financial planners $\left(x_{i}^{f} \forall i\right)$ and secretaries $\left(x_{i}^{s}\right.$ $\forall i$ ) can be satisfied by $n$ tranches $\phi_{1 p} d_{2}, d_{3}, \mathrm{~K}, d_{n}$ of the risky project return $R_{1}, R_{2}, \ldots R_{n}$.

Proof: The proof will be by construction. Let $d_{1}=R_{1}, d_{2}=R_{2}-R_{1}, d_{3}=R_{3}-R_{2}, \ldots$, $d_{n}=R_{n}-R_{n-1}$ be tranches in descending order of seniority. Then the return vectors of the $n$ tranches $d_{1}, d_{2}, d_{3}, . ., d_{n}$ across different states of the world are given by

$$
\begin{gathered}
\tilde{d}_{1}=\left[R_{1}, R_{1}, \ldots \ldots R_{1}\right], \\
\tilde{d}_{2}=\left[0, R_{2}-R_{1}, R_{2}-R_{1} \ldots \ldots R_{2}-R_{1}\right], \\
\tilde{d}_{3}=\left[0,0, R_{3}-R_{2}, R_{3}-R_{2} \ldots \ldots R_{3}-R_{2}\right],
\end{gathered}
$$

and

$$
\tilde{d}_{n}=\left[0,0,0,0 \ldots \ldots R_{n}-R_{n-1}\right]
$$


A financial planner's portfolio yields the return vector $\left(x_{1}^{f}, x_{2}^{f} \ldots \ldots . x_{n}^{f}\right)$. Since $x_{i}^{f}$ is

monotonically increasing in $i$, if the financial planner buys $\frac{x_{1}^{f}}{R_{1}}$ of the first tranche, $\frac{x_{2}^{f}-x_{1}^{f}}{R_{2}-R_{1}}$ of the second tranche, $\frac{x_{3}^{f}-x_{2}^{f}}{R_{3}-R_{2}}$ of the third tranche up to $\frac{x_{n}^{f}-x_{n-1}^{f}}{R_{n}-R_{n-1}}$ of the last tranche we can replicate the same payoff the financial planners would have obtained with the Arrow securities. That is,

$$
\begin{aligned}
& \frac{x_{1}^{f}}{R_{1}} d_{1}+\frac{x_{2}^{f}-x_{1}^{f}}{R_{2}-R_{1}} d_{2}+\frac{x_{3}^{f}-x_{2}^{f}}{R_{3}-R_{2}} d_{3}+\ldots .+\frac{x_{n}^{f}-x_{n-1}^{f}}{R_{n}-R_{n-1}} d_{n}= \\
& =x_{1}^{f}(1,0,0, \ldots 0)+x_{2}^{f}(0,1,0, \ldots 0)+x_{3}^{f}(0,0,1,0, \ldots 0)+\ldots+x_{n}^{f}(0,0,0, \ldots 1) .
\end{aligned}
$$

The same logic applies to secretaries.

Q.E.D.

The possibility of creating Arrow securities by tranching is closely related to Ross (1976). In fact, if short selling were possible, Arrow securities would simply be a non-degenerate linear transformation of the tranches. In our model, however, short selling is not feasible, since the short seller cannot credibly commit to pay.

While there are many ways to manufacture the Arrow securities needed, tranching is particularly attractive because it does not require parties to verify the state of the world, only the total return. It also corresponds to a structure that we observe a great deal, from bank deposits to the infamous Collateralized Debt Obligations (CDOs). Consistent with the model, CDOs became popular as riskless assets at a time of a shortage of treasuries (Gorton and Ordonez, 2013).

\subsection{Distribution of ownership of the various tranches}

Having established that tranches are a convenient way to achieve the same payoff as that obtained by Arrow securities, we ask next how the various tranches will be allocated across investors. Proposition 
4 says that financial planners will invest more in senior tranches and secretaries will invest more in junior tranches.

Proposition 4: The amount invested by a financial planner in tranche $k$

$$
\frac{x_{k}^{f}-x_{k-1}^{f}}{R_{k}-R_{k-1}}
$$

is strictly decreasing in $k=1, \ldots n$ (where $x_{0}^{f}=R_{0}=0$ ). The amount invested by a secretary in tranche $k$

$$
\frac{x_{k}^{s}-x_{k-1}^{s}}{R_{k}-R_{k-1}}
$$

is strictly increasing in $k=1, \ldots n$ (where $\left.x_{0}^{s}=0\right)$.

Proof: Using Proposition 1 we can write

$$
\frac{x_{k}^{f}-x_{k-1}^{f}}{R_{k}-R_{k-1}}=\frac{e\left(R_{k}^{\frac{1}{2}}-R_{k-1}^{\frac{1}{2}}\right) S}{R_{k}-R_{k-1}}
$$

which is strictly decreasing in $k$ since $R^{\frac{1}{2}}$ is a strictly concave function. Also from (3.1),

$$
\frac{x_{k}^{f}-x_{k-1}^{f}}{R_{k}-R_{k-1}}+\frac{x_{k}^{s}-x_{k-1}^{s}}{R_{k}-R_{k-1}}=2 e,
$$

and so $\frac{x_{k}^{s}-x_{k-1}^{s}}{R_{k}-R_{k-1}}$ must be strictly increasing in $k$.

Q.E.D.

\subsection{Welfare effects of losses in different tranches}

Now we want to study the differential macroeconomic and welfare effects of losses in different tranches. There is an obvious reason why a loss suffered by a very senior tranche has worse welfare consequences: since the tranche is senior, it is impaired only when the loss in the underlying investment is so severe as to go through all the other layers. Hence, a loss in a very senior tranche is an indicator of a very negative realization of the state of the world. 
To eliminate this effect, we assume that each tranche is managed by a single, separate fund and that one of these funds faces an unexpected loss due to an accounting fraud (a "Madoff" shock), i.e., a totally idiosyncratic event. A limited number of large funds could, of course, have some market power. To avoid this complication we assume that an entry threat forces them to behave in a competitive way ${ }^{2}$.

It is now legitimate to ask which fund's losses will have the worst impact on the economy.

To repeat, then, we assume that there is one fund managing each tranche. Suppose that the economy has arrived at the beginning of period 2, and it is known that state $i$ has occurred. At this point the fund managing tranche $k$ experiences an unanticipated shock: a small (infinitesimal) unexpected change in its wealth equal to $d \varepsilon$. (We are assuming that state $i$ is such that tranche $k$ is worth a strictly positive amount, i.e., $k \leq i$.) This wealth shock is distributed among financial planners and secretaries according to their relative holdings of tranche $k$. Recall that a financial planner holds $\frac{x_{k}^{f}-x_{k-1}^{f}}{R_{k}-R_{k-1}}$ units and a secretary $\frac{x_{k}^{s}-x_{k-1}^{s}}{R_{k}-R_{k-1}}$ units. These sum to $2 e$, and so the wealth changes in the realized state $i$ will satisfy

$$
\begin{aligned}
& d x_{i}^{f}=\frac{x_{k}^{f}-x_{k-1}^{f}}{R_{k}-R_{k-1}} \frac{d \varepsilon}{2 e}, \\
& d x_{i}^{s}=\frac{x_{k}^{s}-x_{k-1}^{s}}{R_{k}-R_{k-1}} \frac{d \varepsilon}{2 e} .
\end{aligned}
$$

If we define

$$
\lambda_{k}=\frac{x_{k}^{f}-x_{k-1}^{f}}{R_{k}-R_{k-1}} \frac{1}{2 e}
$$

we can rewrite this more compactly as

$$
d x_{i}^{f}=\lambda_{k} d \varepsilon, \quad d x_{i}^{s}=\left(1-\lambda_{k}\right) d \varepsilon .
$$

2 Our results generalize to the case of small funds. One difference occurs if the Madoff shock is anticipated; see Section 6.3 below. 
As in Hart and Zingales (2013), we use the sum of utilities of financial planners and secretaries as our measure of welfare. This is reasonable since ex ante each agent is equally likely to be a financial planner or a secretary.

From $(*)$ and $(* *)$, the sum of utilities in state $i$ is

$$
W_{i}=\left[\frac{x_{i}^{f}}{p_{i}^{s}}+\frac{1}{2}\left(p_{i}^{f}\right)^{2}+\frac{x_{i}^{s}}{p_{i}^{f}}+\frac{1}{2}\left(\frac{p_{i}^{s}}{p_{i}^{f}}\right)^{2}\right]
$$

Using (3.3)-(3.4) to solve for $p_{i}^{f}, p_{i}^{s}$, we can write (4.7) as

$$
W_{i}=\left[\frac{\left(x_{i}^{f}\right)^{\frac{1}{2}}}{\left(x_{i}^{f}+x_{i}^{s}\right)^{\frac{1}{4}}}+\frac{1}{2}\left(x_{i}^{f}+x_{i}^{s}\right)+\frac{x_{i}^{s}}{\left(x_{i}^{f}+x_{i}^{s}\right)^{\frac{1}{2}}}+\frac{1}{2} \frac{x_{i}^{f}}{\left(x_{i}^{f}+x_{i}^{s}\right)^{\frac{1}{2}}}\right]
$$

Note that in the absence of the shock $x_{i}^{f}+x_{i}^{s}=2 e R_{i}$.

Differentiating (4.8) with respect to $\varepsilon$ and using (4.6), we obtain, at $\varepsilon=0$,

$$
\frac{d W_{i}}{d \varepsilon}=
$$

$$
\begin{aligned}
& {\left[\frac{\left(2 e R_{i}\right)^{\frac{1}{4}} \frac{1}{2}\left(x_{i}^{f}\right)^{-\frac{1}{2}} \lambda_{k}-\left(x_{i}^{f}\right)^{\frac{1}{2}} \frac{1}{4}\left(2 e R_{i}\right)^{-\frac{3}{4}}}{\left(2 e R_{i}\right)^{\frac{1}{2}}}+\frac{1}{2}+\frac{1}{2} \frac{\left(2 e R_{i}\right)^{\frac{1}{2}}\left(1-\lambda_{k}\right)-x_{i}^{s} \frac{1}{2}\left(2 e R_{i}\right)^{-\frac{1}{2}}}{\left(2 e R_{i}\right)}+\frac{1}{4}\left(2 e R_{i}\right)^{-\frac{1}{2}}\right]} \\
& =\frac{1}{2}\left(x_{i}^{f}\right)^{-\frac{1}{2}} \lambda_{k}\left(2 e R_{i}\right)^{-\frac{1}{4}}-\frac{1}{4}\left(x_{i}^{f}\right)^{\frac{1}{2}}\left(2 e R_{i}\right)^{-\frac{5}{4}}+\frac{1}{2}+\frac{1}{2}\left(1-\lambda_{k}\right)\left(2 e R_{i}\right)^{-\frac{1}{2}}-\frac{1}{4} x_{i}^{s}\left(2 e R_{i}\right)^{-\frac{3}{2}}+\frac{1}{4}\left(2 e R_{i}\right)^{-\frac{1}{2}} .
\end{aligned}
$$

The coefficient of $\lambda_{k}$ in (4.9) is

$$
\frac{1}{2}\left(x_{i}^{f}\right)^{-\frac{1}{2}}\left(2 e R_{i}\right)^{-\frac{1}{4}}-\frac{1}{2}\left(2 e R_{i}\right)^{-\frac{1}{2}},
$$

and this is easily seen to be strictly positive, since

$$
x_{i}^{f}<2 e R_{i}<\left(2 e R_{i}\right)^{\frac{1}{2}}
$$


given that $2 e R_{i}<1$. Hence, we have established that the effect on welfare of a small shock to tranche $k$ is greater if $\lambda_{k}$ is large. But we know from Proposition 4 that $\lambda_{k}$ is decreasing in $k$. Therefore, we have established that the welfare loss from a small negative shock to a tranche will be greater the more senior the tranche is.

The intuition is simple. Each dollar lost has two effects: a direct effect on welfare (equal to a dollar since agents have linear utility) plus an indirect effect on welfare produced by the reduced level of trade (which generates a positive surplus), caused by a reduced level of liquidity. The financial planners are the agents more in need of liquidity. Thus, a loss that falls disproportionately on the shoulders of the financial planners will have disproportionately large welfare consequences. As Proposition 4 shows the people who need liquidity the most (in our model the financial planners) invest more of their wealth in senior funds. In fact, the more so, the more senior they are. Thus, a loss in the more senior funds will fall disproportionately on the shoulders of the financial planners and thus will have a disproportionately large effect on the level of economic activity and a disproportionately large loss in aggregate welfare.

Remark: The above argument also implies that a shock to an industrial firm is (weakly) less serious than an equally-sized shock to a financial intermediary. Suppose that an industrial firm loses $d \varepsilon$. Then this has the effect that $R_{i}$ falls by $d \varepsilon$. But this loss of income "at the top" in state $i$ will affect only the most junior tranche that is solvent in that state, and as we have seen this has a relatively small impact on welfare.

It is natural to ask how large $\frac{d W_{i}}{d \varepsilon}$ is. One's first thought is that $\frac{d W_{i}}{d \varepsilon}>1$, i.e., the effect of a wealth shock will be multiplied, given liquidity constraints. However, this does not have to be the case. In fact, it is even possible that $\frac{d W_{i}}{d \varepsilon}<0$ ! The reason is that a positive wealth shock that affects mainly Secretaries ( $\lambda_{k}$ close to zero) will drive up the price of financial planning services (see (3.4)) and 
therefore reduce the supply and increase the price of secretarial services (see (3.3)). This can make the financial planners so much worse off that the sum of the financial planner and the secretary utilities falls.

However, this cannot happen for very senior tranches, in particular, $k=1$. For $k=1$,

$\lambda_{k}=\frac{x_{1}^{f}}{2 e R_{1}} \geq \frac{x_{i}^{f}}{2 e R_{i}}$ since $x_{j}^{f}=e R_{j}^{\frac{1}{2}} S$ is concave in $R_{j}$. Therefore, a lower bound for $\frac{d W_{i}}{d \varepsilon}$ is given by

(4.9) with $\lambda_{k}$ replaced by $\frac{x_{i}^{f}}{2 e R_{i}}$. Substituting $\lambda_{k}=\frac{x_{i}^{f}}{2 e R_{i}}$ into (4.9) yields

$$
\frac{1}{4} \frac{\left(x_{i}^{f}\right)^{\frac{1}{2}}}{\left(2 e R_{i}\right)^{\frac{5}{4}}}+\frac{1}{2}+\frac{1}{2} \frac{1}{\left(2 e R_{i}\right)^{\frac{1}{2}}}-\frac{1}{4} \frac{x_{i}^{f}}{\left(2 e R_{i}\right)^{\frac{3}{2}}},
$$

which exceeds 1 since $x_{i}^{f}<2 e R_{i}<\left(2 e R_{i}\right)^{\frac{1}{2}}$ implies that

$$
\frac{1}{4} \frac{\left(x_{i}^{f}\right)^{\frac{1}{2}}}{\left(2 e R_{i}\right)^{\frac{5}{4}}}-\frac{1}{4} \frac{x_{i}^{f}}{\left(2 e R_{i}\right)^{\frac{3}{2}}} \geq 0
$$

The conclusion is that a negative shock to the most senior tranche causes a welfare loss that is greater than the shock itself.

We may summarize the main point of this section as follows: If consumers obtain their Arrow securities by holding different tranches on the economy's total return, then a shock to an intermediary managing a senior tranche has greater welfare consequences than a shock to an intermediary managing a junior tranche.

This results seems consistent with the different impact that the subprime crisis had on the economy vis-à-vis the bursting of the internet bubble. Brunnermeier (2009) estimates that during the 2007-8 financial crisis the loss from subprime mortgages was only \$0.5trillion, a fraction of the \$7.1 trillion lost during the dot-com crash. ${ }^{3}$ In spite of this difference, the dot-com crash had very mild effects

3 The market cap of the Dow Jones Wilshire 5000 at the end of Q1 in 2000 was approximately \$16 trillion. Between 2000 Q1 and 2003 Q1 the index lost 43\% of its valuation, i.e. \$7.1 trillion of wealth was lost. 
on the economy, while the subprime crisis had devastating ones. Our interpretation is that the former losses were born by people with low liquidity needs.

\section{Non-pledgeable Equilibrium when $2 e R_{n}>1$ and $R_{n}$ is "large"}

We now consider how the analysis changes when in state $n$ there is enough liquidity, so that $p_{n}^{f}=p_{n}^{s}=1$ and the level of trade is efficient. This case is actually much simpler and will permit a study of fiscal policy in Section 6. To simplify matters we continue to assume that $2 e R_{i}<1$ for all $i<n$.

Proposition 5. Suppose $e R_{n}-1 \geq \sum_{i=1}^{n-1} \frac{\pi_{i}\left(e R_{i}\right)^{\frac{1}{4}}}{\pi_{n} 2^{\frac{3}{4}}}$ and $2 e R_{i}<1$ for all $i<n$. Then there is a unique nonpledgeable equilibrium characterized by

$$
\begin{aligned}
& q_{i}=\frac{\pi_{i} q_{n}}{\pi_{n}\left(2 e R_{i}\right)^{\frac{3}{4}}}, \\
& x_{i}^{f}=2 e R_{i} \\
& x_{i}^{s}=0, \\
& p_{i}^{f}=\left(2 e R_{i}\right)^{\frac{1}{2}} \\
& p_{i}^{s}=\left(2 e R_{i}\right)^{\frac{3}{4}}
\end{aligned}
$$$$
\text { for all } i<n \text {; }
$$

and for $i=n$,

$$
q_{n}=\frac{1}{\sum_{i=1}^{n-1} \frac{\pi_{i} R_{i}}{\pi_{n}\left(2 e R_{i}\right)^{\frac{3}{4}}}+R_{n}}
$$




$$
\begin{gathered}
x_{n}^{f}=e R_{n}-\sum_{i=1}^{n-1} \frac{\pi_{i}\left(e R_{i}\right)^{\frac{1}{4}}}{\pi_{n} 2^{\frac{3}{4}}} \\
x_{n}^{s}=e R_{n}+\sum_{i=1}^{n-1} \frac{\pi_{i}\left(e R_{i}\right)^{\frac{1}{4}}}{\pi_{n} 2^{\frac{3}{4}}} \\
p_{n}^{f}=p_{n}^{s}=1 .
\end{gathered}
$$

Proof: Note that $x_{i}^{f}>0$ for all $i$ and so the first order condition for $(*)$ is

$$
\frac{\pi_{i}}{q_{i} p_{i}^{s}}=k_{1} \quad \text { for all } i
$$

On the other hand, the first order condition for $(* *)$ is

$$
\frac{\pi_{i}}{q_{i} p_{i}^{f}} \leq k_{2} \quad \text { for all } i
$$

with equality if $x_{i}^{s}>0$. We also know that in state $i<n$, prices will be strictly less than 1 and so (3.3)-

(3.4) describe the equilibrium in the goods market. Hence, by (3.2),

$$
\begin{aligned}
& p_{i}^{f}=\left(2 e R_{i}\right)^{\frac{1}{2}} \\
& p_{i}^{s}=\left(x_{i}^{f}\right)^{\frac{1}{2}}\left(2 e R_{i}\right)^{\frac{1}{4}},
\end{aligned}
$$

for $i<n$.

We now show that the above implies $x_{i}^{s}=0$ for all $i<n$. Suppose not: $x_{j}^{s}>0$ for some $j<n$.

Then, (5.1)-(5.2) at $i=n$ imply:

$$
\frac{k_{2}}{k_{1}} \geq 1
$$

since $p_{n}^{f}=p_{n}^{s}=1$. On the other hand, (5.1)-(5.2) at $i=j$ imply: 


$$
\frac{k_{2}}{k_{1}}=\frac{p_{j}^{s}}{p_{j}^{f}}=\frac{\left(x_{j}^{f}\right)^{\frac{1}{2}}}{\left(2 e R_{j}\right)^{\frac{1}{4}}} .
$$

Hence,

$$
\left(x_{j}^{f}\right)^{\frac{1}{2}} \geq\left(2 e R_{j}\right)^{\frac{1}{4}}
$$

which is impossible since, from (3.2), $x_{j}^{f} \leq 2 e R_{j}<\left(2 e R_{j}\right)^{\frac{1}{2}}$, given that $2 e R_{j}<1$.

Therefore, $x_{i}^{s}=0$ for all $i<n$, and, since secretaries have the wealth to buy some securities, $x_{n}^{s}>0$. It follows that

$$
x_{i}^{f}=2 e R_{i} \quad \text { for all } i<n,
$$

and so we can rewrite (5.4) as

$$
p_{i}^{s}=\left(2 e R_{i}\right)^{\frac{3}{4}} \quad \text { for all } i<n .
$$

Combining (5.1) with (5.9), and using $p_{n}^{s}=1$, yields

$$
q_{i}=\frac{\pi_{i} q_{n}}{\pi_{n}\left(2 e R_{i}\right)^{\frac{3}{4}}} .
$$

Finally, we can substitute (5.10) into (3.1) to obtain

$$
q_{n}=\frac{1}{\sum_{i=1}^{n-1} \frac{\pi_{i} R_{i}}{\pi_{n}\left(2 e R_{i}\right)^{\frac{3}{4}}}+R_{n}} .
$$

(5.3), (5.9), (5.10), (5.11), and (5.8) (plus the satisfaction of financial planner and secretary budget constraints) describe a non-pledgeable equilibrium where prices are 1 in the highest state.

There is a further feasibility condition: $x_{n}^{f} \geq 1$, i.e., a financial planner must be able to afford at least one unit of Arrow security $n$ in order to be able to purchase one unit of secretarial services at price 1 in state $n$.( If this were not the case, $p_{i}^{s}<1$ and $p_{i}^{f}=1$.) 
Using (5.8), we require

$$
\sum_{i=1}^{n-1} q_{i} 2 e R_{i}+q_{n} \leq e
$$

which, from (5.10) and (5.11), can be simplified to

$$
e R_{n}-1 \geq \sum_{i=1}^{n-1} \frac{\pi_{i}\left(e R_{i}\right)^{\frac{1}{4}}}{\pi_{n} 2^{\frac{3}{4}}}
$$

Q.E.D.

Remark. Note that (5.13) implies $e R_{n}>1$ and so $2 e R_{n}>2$. In other words $R_{n}$ must be "large".

It is easy to extend the tranching result of Section 4 to this case. A financial planner's holding of tranche $k$, given by $\frac{x_{k}^{f}-x_{k-1}^{f}}{R_{k}-R_{k-1}}$, is constant and equal to $2 e$ for $k=1, \ldots n-1$ from (5.8); while for $k=n$, since $x_{n}^{s}>0, x_{n}^{f}<2 e R_{n}$ and so

$$
\frac{x_{n}^{f}-x_{n-1}^{f}}{R_{n}-R_{n-1}}<2 e
$$

In other words, a financial planner holds equal amounts of all tranches except the most junior one and strictly less of that.

It is also easy to extend the welfare results of Section 4 to show that a negative shock to a senior tranche will create a larger welfare loss than an equivalent shock to the most junior tranche. We will not provide the details here, but instead carry out a similar calculation when we discuss fiscal policy in the next section.

\section{Fiscal Policy}

So far we have not considered how the government might respond to the liquidity problems that we have highlighted. In this section we analyze fiscal policy along the lines of Hart and Zingales (2013). Specifically, we assume that there is a milling technology in period 4 that allows financial planners and 
secretaries to convert wheat into flour, and that they enjoy consuming flour as well as wheat. The government can impose a per unit sales tax on flour - something that the private sector cannot do - and can issue bonds in period 2, after the state of the world is realized, backed by this sales tax. As in Hart and Zingales (2013), we suppose that the government bonds ( $b$ units of them) are handed directly to financial planners (nothing in our analysis relies on the idea that the identity of an agent is nonverifiable).

The details of the milling technology and preferences for flour versus wheat can be found in Hart and Zingales (2013). For our purposes it is enough to rely on the following result from that paper: the government can increase the liquidity of a financial planner in period 2 in state $i$ from $x_{i}^{f}$ to $x_{i}^{f}+b$, but this imposes a loss on the economy in period 4 of $b+\Delta(b)$, where the first term reflects the bond repayment and $\Delta(b)$ is the deadweight loss of the sales tax required to raise $b$.

Here $\Delta(b)$ satisfies

$$
\Delta(0)=0, \quad \Delta^{\prime}(0)=0, \quad \Delta^{\prime \prime}(b)>0 \text { for all } b \geq 0 .
$$

In other words, the marginal deadweight loss is zero when the tax rate is zero but is strictly positive and increasing when the tax rate is positive.

We will be particularly interested in how the government should respond to a Madoff shock. However, given that there is a shortage of liquidity in the economy, the government will want to respond even in the absence of such a shock. Thus, we will analyze the optimal fiscal policy with and without a shock.

Analyzing fiscal policy in the model of Section 3 turn out to be hard, and so we will focus on the model of Section 5 where $2 e R_{n}>1$ and $R_{n}$ is "large". We will suppose that the government chooses fiscal policy in state $i$ in period 2 to maximize the sum of financial planner and secretary utilities. We will also assume that the government cannot commit to its fiscal policy in advance: the government will choose $b_{i}$ in state $i$ to maximize the sum of financial planner and secretary utilities after $x_{i}^{f}, x_{i}^{s}$ are determined.

\subsection{Equilibrium in the Absence of a Shock}


Let's consider the case there is no shock and take the non-intervention equilibrium in Proposition 5 as a starting point. Clearly, there is no need for intervention in state $n$ since the efficient level of trade is realized there. Consider $i<n$. If the government issues $b_{i}$ units of bonds to a financial planner (each bond pays one unit of wheat in period 4 in state $i$ ), then since $x_{i}^{f}=2 e R_{i}, x_{i}^{s}=0$, the new equilibrium in the goods market is given by

$$
\begin{aligned}
& \frac{2 e R_{i}+b_{i}}{p_{i}^{s}}=\frac{p_{i}^{s}}{p_{i}^{f}}, \\
& \frac{2 e R_{i}+b_{i}}{p_{i}^{f}}=p_{i}^{f}, \text { for } i=1, \ldots n-1 .
\end{aligned}
$$

That is,

$$
p_{i}^{f}=\left(2 e R_{i}+b_{i}\right)^{\frac{1}{2}}, \quad p_{i}^{s}=\left(2 e R_{i}+b_{i}\right)^{\frac{3}{4}}
$$

From $\left(^{*}\right)$ and $(* *)$, the sum of financial planner and secretary utilities in state $i$ is

$$
\begin{aligned}
W_{i} & =\left[\frac{x_{i}^{f}+b_{i}}{p_{i}^{s}}+\frac{1}{2}\left(p_{i}^{f}\right)^{2}+\frac{1}{2}\left(\frac{p_{i}^{s}}{p_{i}^{f}}\right)^{2}-b_{i}-\Delta\left(b_{i}\right)\right] \\
& =\left[\left(2 e R_{i}+b_{i}\right)^{\frac{1}{4}}+\frac{1}{2}\left(2 e R_{i}+b_{i}\right)+\frac{1}{2}\left(2 e R_{i}+b_{i}\right)^{\frac{1}{2}}-b_{i}-\Delta\left(b_{i}\right)\right] .
\end{aligned}
$$

The government will choose $b_{i}$ to maximize $W_{i}$. Since $W_{i}$ is strictly concave in $b_{i}$, the following first order condition is necessary and sufficient:

$$
\frac{1}{4}\left(2 e R_{i}+b_{i}\right)^{-\frac{3}{4}}+\frac{1}{2}+\frac{1}{4}\left(2 e R_{i}+b_{i}\right)^{-\frac{1}{2}}-1=\Delta^{\prime}\left(b_{i}\right) .
$$

Note that the left-hand side of (6.6) is strictly positive when $b_{i}=0$ and zero when $2 e R_{i}+b_{i}=1$, and so the optimal $b_{i}$ will satisfy $0<b_{i}<1-2 e R_{i}$.

Now suppose that agents anticipate that the government will choose $b_{i}$ in each state $i<n$ to satisfy (6.6). Will they change their ex-ante behavior ? We argue that they will not: in the 
rational expectations equilibrium $x_{i}^{f}=2 e R_{i}, x_{i}^{s}=0$. To see this set the new price in state $i$ to be as in (6.4).

Also let

$$
q_{i}=\frac{\pi_{i} q_{n}}{\pi_{n}\left(2 e R_{i}+b_{i}\right)^{\frac{3}{4}}}
$$

$$
q_{n}=\frac{1}{\sum_{i=1}^{n-1} \frac{\pi_{i} R_{i}}{\pi_{n}\left(2 e R_{i}+b_{i}\right)^{\frac{3}{4}}}+R_{n}} .
$$

Then, it is easy to see that (5.1) is satisfied, while (5.2) holds with strict inequality for $i<n$. So $x_{i}^{s}=0$ for state $i<n$. Hence, if we set $x_{i}^{f}=2 e R_{i},(3.2)$ is satisfied for $i<n$. Finally, the feasibility condition (5.13) becomes

$$
e R_{n}-1 \geq \sum_{i=1}^{n-1} \frac{\pi_{i}\left(e R_{i}\right)}{\pi_{n}\left(2 e R_{i}+b_{i}\right)^{\frac{3}{4}}},
$$

which is implied by (5.13).

Thus, we have constructed a new equilibrium with government intervention where financial planners continued to hold all the Arrow securities in state $i=1, \ldots n-1$, and the government optimizes accordingly. Note that since $x_{i}^{f}=2 e R_{i}$ for all $i=1, \ldots n-1$, and $x_{n}^{f}<2 e R_{n}$, the tranching results of Section 4 and 5 continue to hold.

\subsection{Unanticipated Madoff Shock}


Let us now consider how the government will respond to an unanticipated Madoff shock $^{4}$. Note that in state $i<n$ only senior tranches are in the money (tranches $\leq i$ ), and since financial planners hold all these tranches ( $x_{i}^{s}=0$ for all $i<n$ ), it does not matter which tranche is hit by the Madoff shock. Thus, if we are concerned with how government intervention depends on the seniority of the tranche hit, the interesting case is when we are in state $n$.

In state $n$ a small Madoff shock will have no effect if $x_{n}^{f}>1$. So let's assume that the financial planners are just on the margin in terms of liquidity: $x_{n}^{f}=1$. Note that $x_{n}^{f}+x_{n}^{s}=2 e R_{n}>1$, so that for small shocks there will be enough liquidity in the market for financial planner services to sustain $p_{n}^{f}=1$.

Suppose that there is a small (negative) shock $d \varepsilon$ to the aggregate amount of liquidity, which is divided among financial planners and secretaries as in (4.6). Before the shock the government had a zero fiscal policy in state $n\left(b_{n}=0\right)$, but after the shock it will intervene. As we have just argued, $p_{n}^{f}=1$ after the shock, and so the equilibrium in the secretary market is given by

$$
\frac{x_{n}^{f}+b_{n}}{p_{n}^{s}}=p_{n}^{s},
$$

i.e.,

$$
p_{n}^{s}=\left(x_{n}^{f}+b_{n}\right)^{\frac{1}{2}}
$$

Welfare in state $n$ after the shock is therefore given by

\footnotetext{
${ }^{4}$ We continue to assume that the government maximizes the sum of financial planner and secretary utilities even though this welfare criterion may not be so compelling in the case of an unanticipated shock.
} 


$$
\begin{aligned}
W_{n} & =\left[\frac{x_{n}^{f}+b_{n}}{p_{n}^{s}}+\frac{1}{2}\left(p_{n}^{f}\right)^{2}+\frac{x_{n}^{s}}{p_{n}^{f}}+\frac{1}{2}\left(\frac{p_{n}^{s}}{p_{n}^{f}}\right)^{2}-b_{n}-\Delta\left(b_{n}\right)\right] \\
& =\left[\left(x_{n}^{f}+b_{n}\right)^{\frac{1}{2}}+\frac{1}{2}+x_{n}^{s}+\frac{1}{2}\left(x_{n}^{f}+b_{n}\right)-b_{n}-\Delta\left(b_{n}\right)\right] .
\end{aligned}
$$

$W_{n}$ is strictly concave in $b_{n}$ and so the following first order condition is necessary and sufficient:

$$
\frac{1}{2}\left(x_{n}^{f}+b_{n}\right)^{-\frac{1}{2}}-\frac{1}{2}=\Delta^{\prime}\left(b_{n}\right)
$$

We can use (6.13) to compute $\frac{d b_{n}}{d \varepsilon}$. Differentiating (6.13) with respect to $\varepsilon$, and applying (4.6), yields

$$
\begin{gathered}
-\frac{1}{4}\left(x_{n}^{f}+b_{n}\right)^{-\frac{3}{2}}\left(\lambda_{k}+\frac{d b_{n}}{d \varepsilon}\right)=\Delta "\left(b_{n}\right) \frac{d b_{n}}{d \varepsilon}, \\
\frac{d b_{n}}{d \varepsilon}=\frac{-\frac{1}{4}\left(x_{n}^{f}+b_{n}\right)^{-\frac{3}{2}} \lambda_{k}}{\Delta "\left(b_{n}\right)+\frac{1}{4}\left(x_{n}^{f}+b_{n}\right)^{-\frac{3}{2}}} .
\end{gathered}
$$

Calculating this at $\varepsilon=0$, where $b_{n}=0$ and $x_{n}^{f}=1$, we have

$$
\left.\frac{d b_{n}}{d \varepsilon}\right|_{\varepsilon=0}=\frac{-\frac{1}{4} \lambda_{k}}{\Delta "(0)+\frac{1}{4}}
$$

It follows from (6.16) that the optimal fiscal response in state $n$ to an unanticipated Madoff shock (i.e., a negative $d \varepsilon$ ) is: a) positive; b) will be bigger if the shock hits a senior tranche (where $\lambda_{k}=2 e$ ) than if hits the most junior tranche (where $\lambda_{k}<2 e$ ).

Note that the optimal fiscal response consists of bailing out people not banks. To the extent that people with liquidity needs can be identified, it is cheaper to bail them out directly 
rather than indirectly through banks, since bailing out banks will typically also transfer resources to agents who do not have pressing liquidity needs.

\subsection{Anticipated Madoff Shock}

A natural question to ask is, what happens if a Madoff-shock is anticipated? Suppose, in particular, that agents realize that each fund may be hit by a Madoff shock with some probability. Can they do anything to protect themselves?

In our economy the possibilities for ex ante insurance are very limited: financial planners cannot obtain insurance from secretaries directly since such contracts can be breached ex post. However, funds can get insurance from each other: a fund could enter into an arrangement with another fund that if it is hit by a Madoff shock and the other one is not, then the unlucky fund will receive a transfer from the lucky fund. This is enforceable since we have assumed that fund managers cannot steal money. (Quite what this assumption means if one of the funds is run by a Madoff is another matter!!)

Analyzing the demand for fund insurance is quite complex, not least because, in general, even senior funds will have both financial planners and secretaries as investors and these agents have different preferences: thus it is not clear what the "objective function" of the fund is. One case where one can make progress is in the model of Section 5 since in this case only financial planners invest in senior funds. There one can show that a Madoff shock in a senior fund will reduce not only the utility of the financial planners who invest in the fund, but also the utility of those who do not invest in the fund, the secretaries $^{5}$. Given this externality, if insurance is costly, a fund acting on behalf of its depositors, the financial planners, may choose insufficient, or no, insurance. Under these conditions, our result that a Madoff shock will be more severe if it hits a senior fund, and that the government response should be larger in this case, will continue to hold even when the shock is anticipated.

\section{Very Senior Funds and Banks}

5 This is only true if the fund is large. Thus this part of the argument does not generalize to the case of small funds; see footnote 2 above. 
So far, we have considered only abstract securities. Yet, the most senior tranches held by the financial planners can be interpreted as bank deposits. On the asset side banks invest in financial claims and on the liability side they have a disproportionate share of very senior claims (deposits). Thus, banks are a cost-effective way to manufacture the Arrow securities needed by financial planners and secretaries. In particular, bank deposits play the role of the most senior security held by the agents with the highest liquidity needs (financial planners).

In real-world banks there is an additional feature (not contained in our model) that gives deposits a highly senior status: their callability on demand. If we consider callability on demand as a form of super seniority, money market funds tend to have this feature too, especially if they are (implicitly) guaranteed by the equity of the sponsoring organization (Kacperczyk and Schnabl (2013)) and possibly by the government.

According to this view, what makes banks special is not the nature of their investments (i.e., information-sensitive bank loans, as in Sharpe (1990) and Rajan (1992)) or their interconnectedness (as in Allen and Gale (2000)), but the people who deposit in them. Banks are special because their deposits are held by people with the highest liquidity needs. As a result, losses among depositors have extremely negative macroeconomic consequences because they deprive of liquidity the agents who need liquidity the most to support their purchases. A loss in their liquidity buffer will lead these agents to curtail their demand for goods and services, reducing the income (and the ability to pay) of other agents in the economy. This effect may reduce the level of economic activity and the aggregate welfare by a multiple of the loss borne.

The amplified effect of a loss imposed on senior claims is not unique to banks, but is shared by money market funds, since they provide an almost perfect substitute for deposits for agents who need liquidity. As a result, losses borne by money market fund investors would have 
similarly disruptive effects on the economy. Consistent with this interpretation, in 2008 money market funds were bailed out in a way similar to banks, even though their lending was not “special” and they were not highly interconnected.

The same logic that applies to banks and money market mutual funds applies to a lesser extent to bonds in general, in particular secured and highly rated bonds. These bonds are also held in higher proportion by people who need liquidity the most. Hence, losses born by bondholders can have some of the same macroeconomic consequences (albeit less severe) as losses borne by depositors. This result might explain why governments are so reluctant to let bondholders suffer a loss.

This simple theory of banking is also able to explain why banks (and money market mutual funds) need to have deposits that do not fluctuate in value. Depositors are the agents with the highest need for liquidity and thus they demand insurance against possible falls in the value of their investments, even if they are risk neutral. This insurance is provided by the agents less in need of liquidity (in our model the secretaries). Finally, this insurance component can explain why the yield of deposits and of very shortterm U.S. treasury bills is lower than the curve of risk and return would predict (Krishnamurthy and Vissing-Jorgensen, 2012).

\section{Conclusions}

This paper explains why - in a complete market framework with pledgeability constraints -- there is a demand for relatively safe assets for transaction purposes. It also explains why agents in need of liquidity invest disproportionately in this asset and why losses imposed on this type of asset have a disproportionate impact on the economy.

The characteristic of this relatively safe asset is that it is very senior, just like deposits in a modern bank. Our argument is that the essence of banks is that bank deposits are held disproportionately by people in need of liquidity. In other words, banks are where the liquidity is. 


\section{References}

Allen, Franklin and Douglas Gale, 2000, “Financial Contagion”, The Journal of Political Economy, Volume 108, Issue 1 (Feb., 2000), 1-33.

Baumol, W, 1956, “The Transactions Demand for Cash: An Inventory Theoretic Approach”, Quarterly Journal of Economics, November Vol. 66, p.545-556

Brunnermeier, Markus K. “Deciphering the Liquidity and Credit Crunch 2007-2008, Journal of Economic Perspectives, Volume 23, Number 1, p.77-100, (2009)

Ricardo J. Caballero, “On the Macroeconomics of Asset Shortages” in The Role of Money: Money and Monetary Policy in the Twenty-First Century. The Fourth European Central Banking Conference 9-10 November 2006, Andreas Beyer and Lucrezia Reichlin, editors. Pages 272-283.

Caballero, Ricardo J., Emmanuel Farhi, and Pierre-Olivier Gourinchas. 2008. "An Equilibrium Model of "Global Imbalances" and Low Interest Rates." American Economic Review, 98(1): 358-93.

DeMarzo, Peter M., 2005, “The pooling and tranching of securities: A model of informed Intermediation”, Review of Financial Studies 18, 1-35.

Diamond, Douglas W. and Philip Dybvig, 1983, "Bank runs, deposit insurance and Liquidity”, Journal of Political Economy 91, 401-419.

Gorton Gary and Guillermo Ordonez, 2013, “The Supply and Demand for Safe Assets”, NBER working paper.

Hanson, Samuel G., Andrei Shleifer, Jeremy C. Stein, and Robert W. Vishny, 2014, "Banks as Patient Fixed Income Investors,” Fed working paper.

Hart, O., and L. Zingales. 2013. “Liquidity and Inefficient Investments”, NBER working paper.

Kacperczyk, Marcin and Philipp Schnabl, 2013, “How Safe are Money Market Funds?” The Quarterly Journal of Economics.

Krishnamurthy, Arvind and Annette Vissing-Jorgensen, 2012, “The Aggregate Demand for Treasury Debt.” Journal of Political Economy, 120, 233-267.

Mian, Atif and Amir Sufi, 2014, House of Debt, University Of Chicago Press

Rajan, Raghuram, 1992, “Insiders and Outsiders: The Choice between Informed and Arm'sLength Debt”, Journal of Finance 47, 1367-1400. 
Ross, Stephen, “Options and Efficiency”, The Quarterly Journal of Economics (1976) 90 (1): 7589

Sharpe, Steven A., 1990, “Asymmetric Information, Bank Lending and Implicit Contracts: A Stylized Model of Customer Relationships”, Journal of Finance 45, 1069-1087

Stein, Jeremy. 2012, “Monetary Policy as Financial-Stability Regulation”, Quarterly Journal of Economics 127, no. 1: 57-95.

Tobin, James, 1956, “The Interest Elasticity of the Transactions Demand for Cash”, Review of Economics and Statistics, August vol 38, n.3, p 241-247. 


\section{Appendix}

In the text we considered the case where $x_{i}^{s}>0$ for all $\mathrm{i}$. In this appendix we show that the analysis generalizes to the case where $x_{i}^{s}=0$ for some $i$.

We show first that secretaries will be at the corner solution in the low states. We know from the first order condition for $(*)$ and $(* *)$ that

$$
\frac{\pi_{i}}{q_{i} p_{i}^{s}}=k_{1} \quad \text { for all } i
$$

$$
\frac{\pi_{i}}{q_{i} p_{i}^{f}} \leq k_{2} \text { for all } i \text {, with equality for some } i \text {. }
$$

Suppose that

$$
\frac{\pi_{m}}{q_{m} p_{m}^{f}}<k_{2}
$$

Then, $x_{m}^{s}=0$ and so from (3.2)-(3.4),

$$
x_{m}^{f}=2 e R_{m}
$$

Substituting into (A.1) yields

$$
q_{m}=\frac{\pi_{m}}{k_{1}\left(2 e R_{m}\right)^{\frac{3}{4}}} .
$$

Consider $j<m$. If we can show that

$$
\frac{\pi_{j}}{q_{j} p_{j}^{f}}<\frac{\pi_{m}}{q_{m} p_{m}^{f}},
$$

then it will follow from (A.2) that $x_{m}^{s}=0$. But we know that, since $R_{j}<R_{m}$,

$$
x_{j}^{f} \leq 2 e R_{j}<2 e R_{m}^{\frac{1}{2}} R_{j}^{\frac{1}{2}}
$$

and so

$$
\left(x_{j}^{f}\right)^{\frac{1}{2}}<(2 e)^{\frac{1}{2}} R_{i}^{\frac{1}{4}} R_{j}^{\frac{1}{4}}
$$


This implies, using (3.2)-(3.4), that

$$
p_{j}^{s}=\left(x_{j}^{f}\right)^{\frac{1}{2}}\left(2 e R_{j}\right)^{\frac{1}{4}}<(2 e)^{\frac{3}{4}} R_{m}^{\frac{1}{4}} R_{j}^{\frac{1}{2}} .
$$

On the other hand, from (3.4) and (3.2),

$$
p_{j}^{f}=\left(2 e R_{j}\right)^{\frac{1}{2}} .
$$

Combining (A.5), (A.12), (A.6), and (A.1) yields

$$
\frac{p_{m}^{f}}{p_{j}^{f}}=\left(\frac{R_{m}}{R_{j}}\right)^{\frac{1}{2}}<\frac{p_{m}^{s}}{p_{j}^{s}}=\frac{\pi_{m} q_{j}}{\pi_{j} q_{m}},
$$

which in turn implies (A8). Thus, we have established that if $x_{m}^{s}=0$, then $x_{j}^{s}=0$ for $j<m$. In other words, there exists $r$ such that secretaries are at a corner solution in the low states: $x_{i}^{s}=0$ for $i=1, \ldots r, x_{i}^{s}>0$ for $i=r+1, \ldots, n$.

A non-pledgeable equilibrium can therefore be characterized as follows (using (3.1)-(3.4) and (*), $(* *))$ :

For some $r$, for $\mathrm{i}=1, \ldots, r$

$$
\begin{gathered}
x_{i}^{f}=2 e R_{i}, \quad x_{i}^{s}=0 \\
p_{i}^{f}=\left(2 e R_{i}\right)^{\frac{1}{2}}, p_{i}^{s}=\left(2 e R_{i}\right)^{\frac{3}{4}} \\
q_{i}=\frac{\pi_{i}}{k_{1}\left(2 e R_{i}\right)^{\frac{3}{4}}} \geq \frac{\pi_{i}}{k_{2}\left(2 e R_{i}\right)^{\frac{1}{2}}}, \text { with strict inequality for } i<r ;
\end{gathered}
$$

and for $i=r+1, \ldots n$,

$$
p_{i}^{f}=\left(2 e R_{i}\right)^{\frac{1}{2}}, p_{i}^{s}=\left(x_{i}^{f}\right)^{\frac{1}{2}}\left(2 e R_{i}\right)^{\frac{1}{4}}
$$

$$
\begin{aligned}
& q_{i}=\frac{\pi_{i}}{k_{1}\left(x_{i}^{f}\right)^{\frac{1}{2}}\left(2 e R_{i}\right)^{\frac{1}{4}}}=\frac{\pi_{i}}{k_{2}\left(2 e R_{i}\right)^{\frac{1}{2}}}, \\
& x_{i}^{f}=\left(\frac{k_{2}}{k_{1}}\right)^{2}\left(2 e R_{i}\right)^{\frac{1}{2}}, \quad x_{i}^{s}=2 e R_{i}-\left(\frac{k_{2}}{k_{1}}\right)^{2}\left(2 e R_{i}\right)^{\frac{1}{2}}>0, \\
& \sum_{i} q_{i} R_{i}=1 \quad \sum_{i} q_{i} x_{i}^{f}=e .
\end{aligned}
$$

Note that the first part of (A.19) follows from (A.18). 
We can use (A.16) and (A.18) to write (A.20) as

$$
\sum_{i}^{r} \frac{\pi_{i}}{k_{1}\left(2 e R_{i}\right)^{\frac{3}{4}}} R_{i}+\sum_{i=r+1}^{n} \frac{\pi_{i}}{k_{2}\left(2 e R_{i}\right)^{\frac{1}{2}}} R_{i}=1
$$

$$
\sum_{i}^{r} \frac{\pi_{i}}{k_{1}\left(2 e R_{i}\right)^{\frac{3}{4}}} 2 e R_{i}+\sum_{i=r+1}^{n} \frac{\pi_{i}}{k_{2}\left(2 e R_{i}\right)^{\frac{1}{2}}}\left(\frac{k_{2}}{k_{1}}\right)^{2}\left(2 e R_{i}\right)^{\frac{1}{2}}=e
$$

Defining $h=\frac{k_{2}}{k_{1}}$, we can further rewrite (A.21) and (A.22) as

$$
\frac{1}{k_{1}}\left[\sum_{i}^{r} \frac{\pi_{i}}{(2 e)^{\frac{3}{4}}} R_{i}^{\frac{1}{4}}+\sum_{i=r+1}^{n} \frac{\pi_{i}}{h(2 e)^{\frac{1}{2}}} R_{i}^{\frac{1}{2}}\right]=1
$$

$$
\frac{1}{k_{1}}\left[\sum_{i}^{r} \pi_{i}\left(2 e R_{i}\right)^{\frac{1}{4}}+\sum_{i=r+1}^{n} \pi_{i} h\right]=e .
$$

We also know from (A.16) and (A.18) that

$$
\left(2 e R_{r}\right)^{\frac{1}{4}} \leq h<\left(2 e R_{r+1}\right)^{\frac{1}{4}} .
$$

(A.23)- (A.25) characterize a non-pledgeable equilibrium.

We now show that if there is a solution to (A.23)- (A.25), it is unique. Start at a solution to (A.23)- (A.25) and graph (A.23) and (A.24) in a figure. It is easy to see that the locus of $\left(k_{1}, h\right)$ satisfying (A.23) is downward-sloping and the locus of $\left(k_{1}, h\right)$ satisfying (A.24) is upward-sloping. Moreover, the first curve asymptotes to the horizontal axis as $k_{1} \rightarrow \infty$ and to a vertical line at $k_{1}>0$ as $h \rightarrow \infty$; while the second curve satisfies $k_{1} \rightarrow \hat{k}_{1}>0$ as $h \rightarrow 0$ and $k_{1} \rightarrow \infty$ as $h \rightarrow \infty$. It follows that the curves have a unique intersection.

Now increase $r$. It is straightforward to show that the downward-sloping curve moves in, while the upward-sloping curves moves to the right. Hence, $h$ falls. But this means that if (A.25) is satisfied at the first level of $r$, it cannot be satisfied at the second.

Hence, there can be at most one equilibrium. But a non-pledgeable equilibrium exists by standard fixed point arguments. So there is exactly one equilibrium. 
It remains to establish Propositions 2-4. The key properties that these propositions depend on are that $x_{i}^{f}, x_{i}^{s}$ are increasing in $i$ and that $x_{i}^{f}$ is concave in $R_{i}$. But it is easy to check that (A.14), (A.19), and (A.25) imply these properties; and furthermore that $\frac{x_{i}^{f}}{R_{i}}$ is constant from $i=1, . ., r$, and strictly decreasing for $i=r+1, \ldots, n$. (In Proposition 4 the word "strictly" must be removed. However, it is still the case that a financial planner's investment in the most senior tranche is strictly greater than his investment in the most junior tranche, and vice versa for secretaries.) 